Research Article

\title{
Comparison of the Effect of Sol-Gel and Coprecipitation Routes on the Properties and Behavior of Nanocomposite Chitosan-Bioactive Glass Membranes for Bone Tissue Engineering
}

\author{
Elke M. F. Lemos, ${ }^{1}$ Sandhra M. Carvalho, ${ }^{1}$ Patrícia S. O. Patrício, ${ }^{2}$ \\ Claudio L. Donnici, ${ }^{3}$ and Marivalda M. Pereira ${ }^{1}$ \\ ${ }^{1}$ NDBio Research Group, Department of Metallurgical and Materials Engineering, Universidade Federal de Minas Gerais, \\ 253 31270-901 Belo Horizonte, MG, Brazil \\ ${ }^{2}$ Department of Chemistry, Centro Federal de Educação Tecnológica de Minas Gerais, 30 421-169 Belo Horizonte, MG, Brazil \\ ${ }^{3}$ Department of Chemistry, Universidade Federal de Minas Gerais, 253 31270-901 Belo Horizonte, MG, Brazil \\ Correspondence should be addressed to Marivalda M. Pereira; mpereira@demet.ufmg.br
}

Received 13 April 2014; Revised 16 August 2014; Accepted 25 September 2014

Academic Editor: Sharmila M. Mukhopadhyay

Copyright (C) 2015 Elke M. F. Lemos et al. This is an open access article distributed under the Creative Commons Attribution License, which permits unrestricted use, distribution, and reproduction in any medium, provided the original work is properly cited.

Recent studies in tissue engineering have highlighted the importance of the development of composite materials based on biodegradable polymers containing bioactive glasses, in particular, composites for high load support and excellent cell viability for potential application in bone regeneration. In this work, hybrid composite films were obtained by combining chitosan with bioactive glass in solution form and in nanoparticle dispersion form obtained by the two different synthesis routes: the sol-gel method and coprecipitation. The bioactive glass served both as a mechanical reinforcing agent and as a triggering agent with high bioactivity. The results of in vitro assays with simulated body fluid demonstrated the formation of a significant layer of fibrils on the surface of the film, with a typical morphology of carbonated hydroxyapatite, reflecting induction of a favorable bioactivity. Maximum tensile stress increased from 42 to $80 \mathrm{MPa}$ to the sample with $5 \%$ wt bioactive glass. In addition, samples containing $5 \%$ and $10 \%$ wt bioactive glass showed a significant increase in cell viability, 18 and $30 \%$ increase compared to the control group. The samples showed significant response, indicating that they could be a potential material for use in bone regeneration through tissue engineering.

\section{Introduction}

Nanoscale systems have generated promising results in bone tissue engineering; a growing consensus of the literature focuses on the development of nanostructured materials based on ceramics or bioactive glasses because of their high capacity for biomineralization [1-4]. The use of nanometer size particles is known to influence the increase in bioactivity of ceramic materials; in addition, the inorganic phase may act as a reinforcing agent for improving the mechanical properties of the material $[5,6]$. The production of nanocomposites based on biodegradable polymers and bioactive glasses has been the focus of extensive studies in the literature, which combines the ability of glass to form a strong bond with the bone tissue surface $[7,8]$. Bioactive glasses in the system $\mathrm{SiO}_{2}-\mathrm{CaO}-\mathrm{P}_{2} \mathrm{O}_{5}$ have been investigated as biomaterials to be introduced into the organic phase due to their osteoconductivity properties. When a bioactive glass is implanted, a biological response is generated at the interface of the material, leading to a chemical bond between the tissue and the material $1[9,10]$. The biomineralization ability of bioactive glasses is related to their composition but is also influenced by their physical properties, such as particle size, porosity, surface area, and morphology [11-13]. 
The introduction of the bioactive phase in the polymeric composites has generally been produced by the sol-gel method, which is a versatile method that allows the incorporation of inorganic components into polymers at the molecular scale and at low temperatures, resulting in a hybrid material or nanocomposite material $[7,14]$.

Chitosan is a natural polymer that has shown promising performance in tissue engineering. This polymer has been extensively studied as a biomaterial because it has unique biomedical properties, mainly due to the ability to biodegrade $[15,16]$, the high biocompatibility [17] with immunogenicity, the ability to act as an antibacterial agent [18], and the antifungal properties [19] in wound healing, in addition to the benefit that the degradation products of chitosan do not generate toxic materials and are not carcinogenic [7, 20]. However, chitosan as a pure material is not ideal for bone regeneration because its osteoconductivity needs to be improved [21]. Because chitosan does not exhibit high bioactivity, it is necessary to combine it with another bioactive material to improve the osteoconductivity [22]. Furthermore, when a cross-linking agent, such as glutaraldehyde, is added to chitosan, it significantly increases its mechanical properties [23]. The mechanical properties are of crucial importance, especially in regard to regeneration of hard tissue such as bone, which requires load support. Therefore, the combination of chitosan and silica-based nanoparticles to form a hybrid nanocomposite is a strategy to address the demands of mechanical loading on bone grafts. There are a few studies demonstrating the interaction at the molecular level of chitosan with silica-based materials [2, 3, 6, 15, 19]. Chitosan has functional groups, such as hydroxyl groups and amines, which have high possibility of rapidly bonding to other functional groups. Hybrids formed from chitosan and silica exhibited an increase of the interfacial interaction with improved mechanical properties [3].

In this work, two strategies were used to produce bioactive nanocomposites: one strategy involves a solution (solgel) and the other strategy involves a nanoparticle dispersion obtained by combination of the sol-gel method and the coprecipitation method. These two synthesis routes were used to produce membranes, which were evaluated in terms of their mechanical properties, bioactivity, and biological synthesis for future use in scaffolds of bone tissue engineering.

\section{Materials and Methods}

Commercial chitosan (high molecular weight and degree of deacetylation 75-85\%), tetraethylorthosilicate (TEOS, 98\%), and triethyl phosphate (TEP-99\%) were supplied by SigmaAldrich, and ammonia $\left(\mathrm{NH}_{3}\right)$ and $\mathrm{Ca}\left(\mathrm{NO}_{3}\right)_{2} \cdot 4 \mathrm{H}_{2} \mathrm{O}(99 \%)$ were supplied by Synth. The composition of the bioactive glass was 60\%: $\mathrm{SiO}_{2}, 36 \%: \mathrm{CaO}$, and $4 \%: \mathrm{P}_{2} \mathrm{O}_{5}(\% \mathrm{~mol})$. A solution of glutaraldehyde $2.0 \% \mathrm{w} / \mathrm{v}$ was obtained by dilution of a commercial solution ( $25 \% \mathrm{w} / \mathrm{v}$, Sigma-Aldrich).

2.1. Bioactive Glass Solution Preparation. The bioactive glass precursor solution was obtained by acid hydrolysis and polycondensation of tetraethylorthosilicate (TEOS
$\left.\left(\mathrm{Si}\left(\mathrm{OC}_{2} \mathrm{H}_{5}\right)_{4}\right)\right)$, alkoxide precursor of $\mathrm{SiO}_{2}$, triethyl phosphate (TEP $\left.\left(\left(\mathrm{C}_{2} \mathrm{H}_{5} \mathrm{O}\right)_{3} \mathrm{PO}_{4}\right)\right)$, and alkoxide precursor $\mathrm{P}_{2} \mathrm{O}_{5}$. The hydrolysis occurred by adding deionized water and was catalyzed by nitric acid. Calcium nitrate $\left(\mathrm{Ca}\left(\mathrm{NO}_{3}\right)_{2} \cdot 4 \mathrm{H}_{2} \mathrm{O}\right)$ was added as a precursor of $\mathrm{CaO}$.

2.2. Bioactive Glass Nanoparticle Dispersion Preparation. The method of preparation of BGNPs was based on previous work $[4,5]$ consisting of combining the sol-gel coprecipitation method. In the first step, TEOS and TEP precursors were hydrolyzed under acidic conditions. The precursors were dispersed in methanol and water, and the $\mathrm{pH}$ was adjusted to $1-2$ by nitric acid. The mixture was kept under magnetic stirring to obtain a transparent sol. In this second step, transparent sol (monodisperse) was condensed separately in alkaline solution. The sol was then dripped in deionized water with ammonium hydroxide under vigorous mechanical agitation. The $\mathrm{pH}$ of the solution was adjusted in the range of 10 to 12 . After $12 \mathrm{~h}$ of mechanical stirring, the suspension was taken to the oven $50^{\circ} \mathrm{C}$ to evaporate the ammonia (until $\mathrm{pH}<$ 8 ). Calcium nitrate was added and kept under mechanical stirring for $24 \mathrm{~h}$. The dispersion obtained was filtered through Millipore filters of $0.22 \mu \mathrm{m}$ and $0.11 \mu \mathrm{m}$; after passing the dispersion through each of the filters, the dispersion was collected and stored for later use. The final appearance of the dispersion was a colorless liquid.

2.3. Hybrid CS-BG Films Preparation. The hybrid films were obtained by mixing $1 \% \mathrm{w} / \mathrm{v}$ chitosan solution with the precursor solution bioactive glass of the following compositions: $10 \mathrm{wt} \%, 20 \mathrm{wt} \%$, and $30 \mathrm{wt} \%$; these materials were then crosslinked with glutaraldehyde corresponding to $3 \%$ of the total weight of chitosan. Films from pure chitosan were produced. The final solution was poured into polypropylene dishes and kept at room temperature for approximately $60 \mathrm{~h}$. They were then placed in an oven $\left(40 \pm 2^{\circ} \mathrm{C}\right)$ for $24 \mathrm{~h}$ for complete drying.

2.4. Nanocomposites CS-BGNP Films Preparation. The nanocomposite films were obtained by dissolving $1 \% \mathrm{w} / \mathrm{v}$ chitosan commercial powder in the previously prepared dispersion of BGNP (item 2.2), based on previous work under acidic conditions, to obtain the following concentrations of nanoparticles in the films compositions: $1 \mathrm{wt} \%, 3 \mathrm{wt} \%, 5 \mathrm{wt} \%$, and $10 \mathrm{wt} \%$. The dissolution procedure consists of the following steps. Deionized water was added to the dispersion BGNP under mechanical stirring; the dispersion was measured to have $\mathrm{pH}$ above 7. Nitric acid was added to obtain $\mathrm{pH}=2.5$. Chitosan powder was added slowly while maintaining the $\mathrm{pH}$ below approximately 4 . After stabilization, the suspension was kept under mechanical stirring for $24 \mathrm{~h}$. Glutaraldehyde, corresponding to $3 \mathrm{wt} \%$ of the total weight of chitosan (the same amount used to synthesize the hybrid films previously described), was added into the suspension, which was subsequently poured into a Petri dish and then kept at room temperature for $60 \mathrm{~h}$. Finally, the suspension was completely dried in an oven $\left(40 \pm 2^{\circ} \mathrm{C}\right)$ for $24 \mathrm{~h}$. 
2.5. In Vitro Bioactivity Tests. The synthesis conditions of the hybrids typically resulted in a product of polymeric character that is sensitive to high temperatures, which prevents the elimination of toxic substances by thermal treatment [24]. When in contact with the culture medium, the dissolution of hybrid products may change the $\mathrm{pH}$ of the medium and the cell growth, promoting lower cell viability. This change requires a neutralization step to reduce the acidity of the samples and to make them more biocompatible. Therefore, to assess the bioactivity, a prestudy of variation of $\mathrm{pH}$ and hybrid nanocomposites in a solution of SBF (kept at $37^{\circ} \mathrm{C}$ ) was conducted. Samples containing $0 \mathrm{wt} \%, 10 \mathrm{wt} \%, 20 \mathrm{wt} \%$, and $30 \mathrm{wt} \%$ of BG and samples containing $0 \mathrm{wt} \%, 1 \mathrm{wt} \%, 3 \mathrm{wt} \%$, and $5 \mathrm{wt} \%$ of BGNP were immersed for zero days, one day, seven days, and 28 days, followed by the measurement of the $\mathrm{pH}$.

The biomineralization tests were performed according to ISO/FDIS 23317:2007 (E) [25-28]. Films with $20 \mathrm{wt} \%$ of either BG or BGNP were used in these tests. The samples in triplicate that were cut to a size of $10 \mathrm{~mm} \times 20 \mathrm{~mm}$ were immersed in SBF (simulated body fluid) and kept for one day, seven days, and 28 days. The quantity of $40 \mathrm{~mL}$ of SBF was used to obey the relationship between the surface area of the sample ( $\mathrm{Sa}$ ) in square millimeters and the volume of $\mathrm{SBF}$ solution (Vs) in milliliters given by $\mathrm{Vs}=\mathrm{Sa} / 10$. The vials containing the samples were placed in a water bath at $37 \pm 2^{\circ} \mathrm{C}$. After removing the samples from the SBF, they were washed and dried at room temperature. The level of mineralization of the films after immersion was evaluated by scanning electron microscopy (SEM). Fourier transform infrared (FTIR) spectroscopy was also used to confirm the presence of the components of carbonated hydroxyapatite (CHA) (Nicolet 380 of ThermoScientific). Moreover, the standard bioactivity ISO/FDIS 23317: 2007 (E) describes that SEM and FT-IR data must be accompanied by analysis of Xray diffraction (XRD) data to confirm the formation of the $\mathrm{CHA}$ and therefore the formation of the CHA layer was also investigated by XRD [29].

2.6. Mechanical Tests. The selection of samples subjected to tensile tests was defined as the most homogeneous region of the films to obtain more representative results in the mechanical test. The samples of the films were subjected to the tensile test to evaluate the tensile strength and the strain at break. The films were subjected to the test with an initial spacing between the gauge lengths of $50 \mathrm{~mm}$. To ensure accurate results, 6-8 samples of each film were submitted to testing. The tests were conducted on the Machine Model 3000 EMIC DL, using a $200 \mathrm{~N}$ load cell, a test speed of $25 \mathrm{~mm} \mathrm{~min}^{-1}$, and a test temperature of $26 \pm 2^{\circ} \mathrm{C}$. The tensile tests were performed according to ASTM D882-10 (Standard Test Method for Tensile Properties of Thin Plastic Sheeting) [30].

2.7. In Vitro Cytotoxicity Tests. The films synthesized were submitted to the first stage of in vitro evaluation by the cytotoxicity test following 10993-5:1999 (Biological evaluation of medical devices; Part 5: tests for in vitro cytotoxicity) [25-28].
TABLE 1: $\mathrm{pH}$ of the medium and the hybrid nanocomposite films as a function of immersion time in SBF.

\begin{tabular}{lcccc}
\hline $\begin{array}{l}\text { Samples } \\
(\mathrm{wt} \%)\end{array}$ & $0 \mathrm{~h}$ & 1 day & 7 days & 28 days \\
\hline CS & 7.40 & 7.45 & 7.35 & 7.40 \\
CS-10\% BG & 7.40 & 7.34 & 7.49 & 7.25 \\
CS-20\% BG & 7.40 & 7.33 & 7.45 & 7.35 \\
CS-30\% BG & 7.40 & 7.32 & 7.50 & 7.22 \\
CS-1\% BGNP & 7.40 & 7.37 & 7.31 & 7.36 \\
CS-3\% BGNP & 7.40 & 7.35 & 7.32 & 7.24 \\
CS-5\% BGNP & 7.40 & 7.31 & 7.29 & 7.28 \\
CS-10\% BGNP & 7.40 & 7.39 & 7.34 & 7.30 \\
\hline
\end{tabular}

The Resazurin cell viability assay was used. Human osteosarcoma cells (SAOS), a commercial line of immortalized cells, were kindly provided by Professor Alfredo Miranda Goes, the Department of Biochemistry and Immunology, UFMG. The cells were cultured in DMEM with 10\% fetal bovine serum (Gibco BRL, NY), penicillin G sodium (10 IU/mL), streptomycin sulfate $(10 \mathrm{mg} / \mathrm{L})$, and 0.25 amphotericin B (Gibco BRL, NY, USA) in an incubator with $5 \% \mathrm{CO}_{2}$ at $37^{\circ} \mathrm{C}$. Samples of the films CS-BG and CS-BGNP with $12 \mathrm{~mm}$ in diameter were placed in 24-well plates and cells were plated $\left(1 \times 10^{4}\right.$ cells $)$ on each sample material. Cells with DMEM and 10\% FBS were used as reference controls, as positive control PBS (2X), and as negative control chips of sterile polypropylene Eppendorf $(0.1 \mathrm{mg} / \mathrm{mL})$ from Eppendorf (Hamburg, Germany). The method of sterilization was ultraviolet radiation for 30 minutes on each side of the samples [31-33]. Tests were performed in triplicate $(n=3)$ for each sample type. After $72 \mathrm{~h}$, all of the media were aspirated, and $900 \mu \mathrm{L}$ of culture medium with serum was placed into each well. One hundred microliters of Resazurin $(0.1 \mathrm{mg} / \mathrm{mL}$, Sigma-Aldrich, USA) was added in each well, which was placed in an incubator for a period of $18 \mathrm{~h}$ with $5 \% \mathrm{CO}_{2}$ at $37^{\circ} \mathrm{C}$. Then, $100 \mu \mathrm{L}$ was removed from each well and transferred to 96-well flat plates, and the measurement was performed using a spectrophotometer (1.6 Adap, Anthos Labtec Instruments) with two filters of $570 \mathrm{~nm}$ and $590 \mathrm{~nm}$.

\section{Results and Discussion}

3.1. Qualitative Assessment. Homogeneous films were produced by the technique of evaporation of the solvent and visually exhibited a yellowish transparent glossy surface. The films and hybrid nanocomposites containing higher levels of bioactive glass ( $30 \mathrm{wt} \%$ of BG) underwent a change in their physical appearance after drying: the structure retracted and exhibited a loss of flexibility, thereby making the surface appear opaque. This behavior is clearly observed in the films with $30 \mathrm{wt} \%$ of bioactive glass.

3.2. Tests of the In Vitro Bioactivity. Table 1 presents the $\mathrm{pH}$ values of the medium after immersion of the nanocomposite. The $\mathrm{pH}$ values obtained ranged from 7.22 to 7.50 ; therefore, 


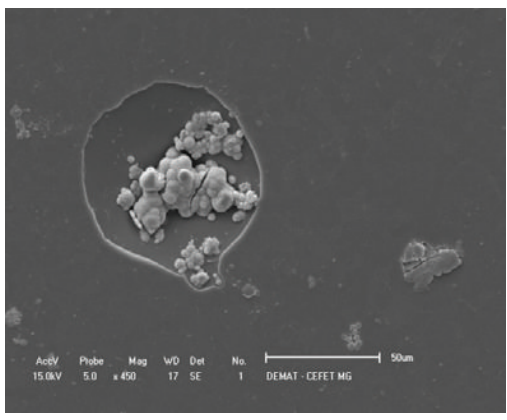

(A)

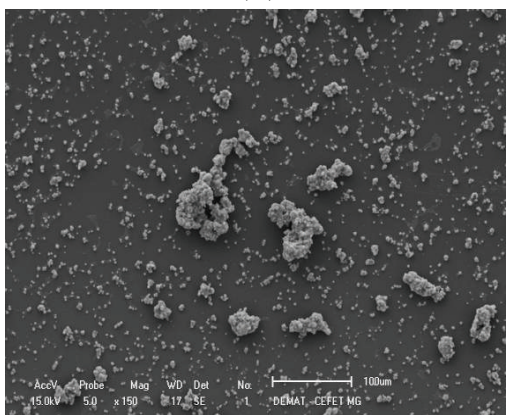

(B)

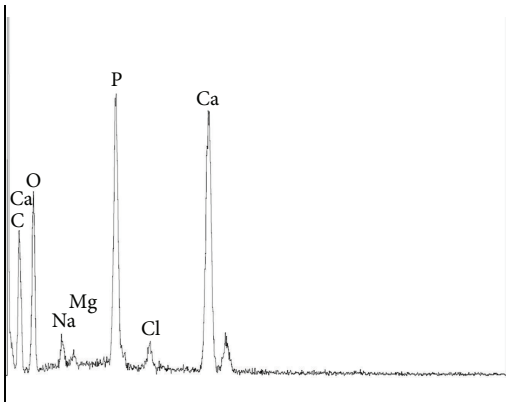

(C)

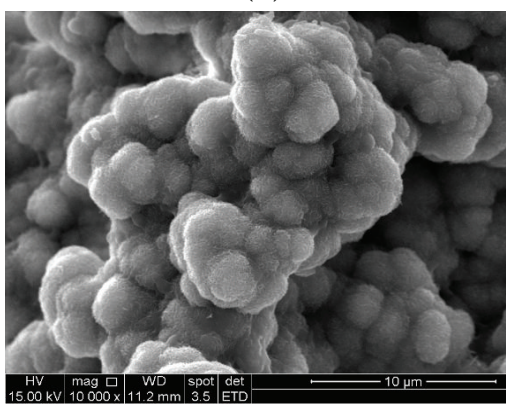

(D)

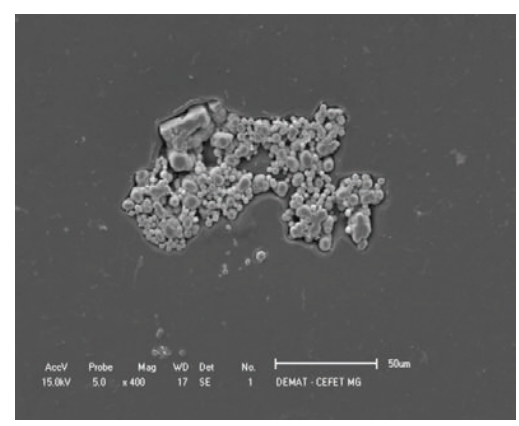

(a)

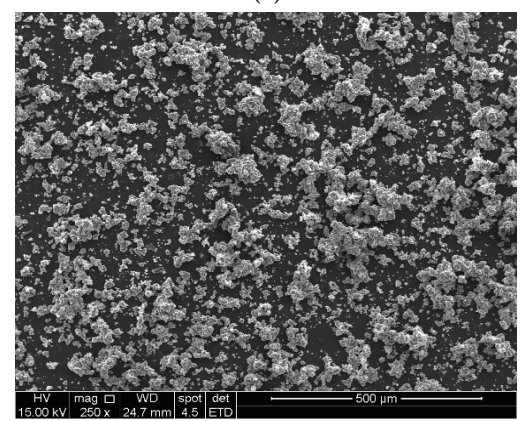

(b)

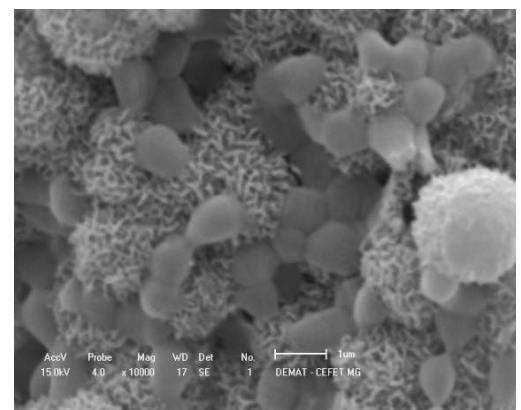

(c)

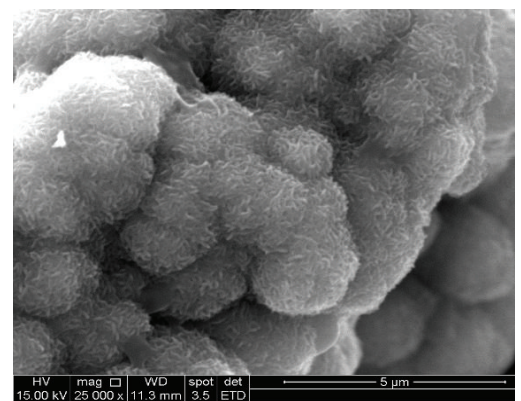

(d)

FIGURE 1: SEM images of the surface of the films with $20 \mathrm{wt} \%$ BG immersed in SBF for one day ((A), (a)), seven days ((B), (b)), or 28 days (c-D-d). EDS image of the film immersed in SBF for 28 days (C).

there was not a significant change of $\mathrm{pH}$ in the solution of PBS, indicating that the samples were stable in this aspect and indicating that a neutralization step was not required.

SEM images of the surface of the films with $20 \mathrm{wt} \% \mathrm{BG}$ immersed in SBF for one day, seven days, or 28 days are shown in Figure 1. Gradual formation of CHA with increasing days of immersion in SBF was observed in the SEM images (Figure $1(\mathrm{~A}-\mathrm{d})$ ).
On the surface of the hybrid films (20wt\% of BG), a homogeneous morphology was observed due to the dispersion of small crystals with sizes less than $5 \mu \mathrm{m}$, which characterizes the formation of the CHA layer. Initially, the apatite grains were more isolated (Figure 1(A-a)) and, after seven days, exhibited a uniform and thicker layer on the surface of the hybrid (Figure 1(B-b)). After 28 days the film surface was completely covered by $\mathrm{CHA}$, exhibiting a more 


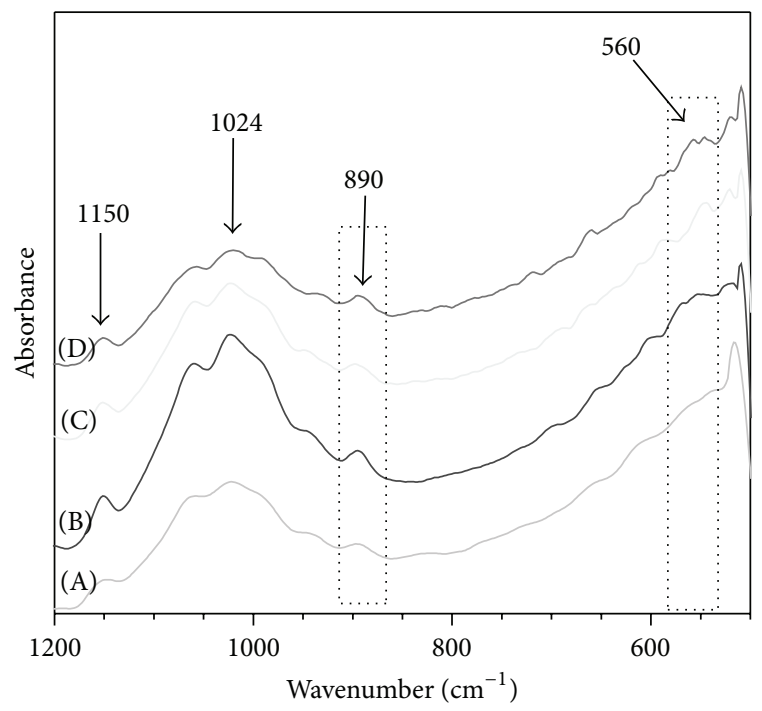

(a)

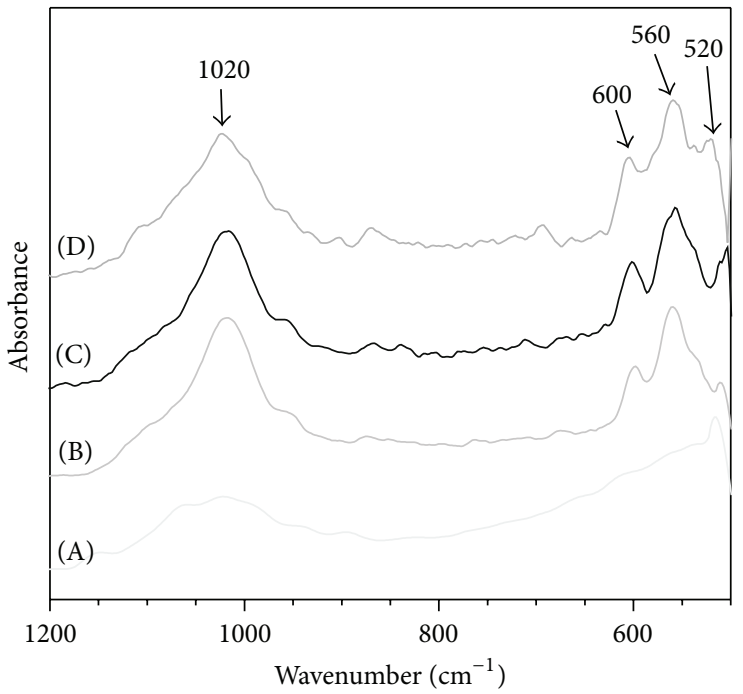

(b)

FIGURE 2: FTIR film after one day of immersion (a) and after 28 days of immersion in SBF (b): (A) CS, (B) 10, (C) 20, and (D) 30 wt\% BG.

intense biological response, according to the increase of the immersion time (Figure 1(c-D-d)). The identification of the chemical composition of these crystals was performed by EDS, which indicated the presence of Ca (Calcium) and P (phosphorus), as shown in Figure 1(C). Although the analysis by EDS does not represent a quantitative analysis, the $\mathrm{Ca}$ and $P$ peaks were very significant in the sample.

The FTIR spectra (Figure 2(a)) for pure chitosan films and for films containing 10,20, and $30 \mathrm{wt} \%$ content of bioactive glass after immersion in SBF immersed for one day to 28 days showed vibration bands at $520 \mathrm{~cm}^{-1}, 560 \mathrm{~cm}^{-1}$, and $600 \mathrm{~cm}^{-1}$ corresponding to the bending vibration of $\mathrm{P}-\mathrm{O}$. These results indicated the formation of a crystalline layer of calcium phosphate. The bands at $600 \mathrm{~cm}^{-1}$ are related to the $\mathrm{PO}_{4}{ }^{2-}$ group, as shown in Figures 2(a) and 2(b). The band at $890 \mathrm{~cm}^{-1}$ that is related to the stretching vibration of the $\mathrm{CO}_{3}{ }^{-2}$ group was more evident in the films with a 10,20 , and $30 \mathrm{wt} \%$ content of bioactive glass, as shown in Figure 2(a). The FTIR spectrum of films containing $30 \mathrm{wt} \%$ bioactive glass after 28 days of immersion, shown in Figure 2(b), reveals a band at $520 \mathrm{~cm}^{-1}$ related to the bending vibration of P-O. Bands at 1024, 1020, and $1150 \mathrm{~cm}^{-1}$ for films with one-day immersion, as shown in Figures 2(a) and 2(b), are indicative of the shift of the $1100 \mathrm{~cm}^{-1}$ band, which is attributed to the stretching P-O. The intensities of the bands increased after 28 days of immersion, indicating the formation of the CHA layer. Films of pure chitosan did not exhibit bands related to the formation of CHA [14, 34, 35].

CHA formation was also recorded by XRD (Figure 3). The XRD patterns of the films revealed a peak with a high intensity at $2 \theta=32^{\circ}$ and another peak with a low intensity at $2 \theta=26^{\circ}$, which are associated with the planes (211) and (002), respectively $[4,19,36,37]$. These peaks are characteristic of the crystalline phase of CHA according to record 19-274 (JCPDS). However, these two peaks only appear in the hybrid

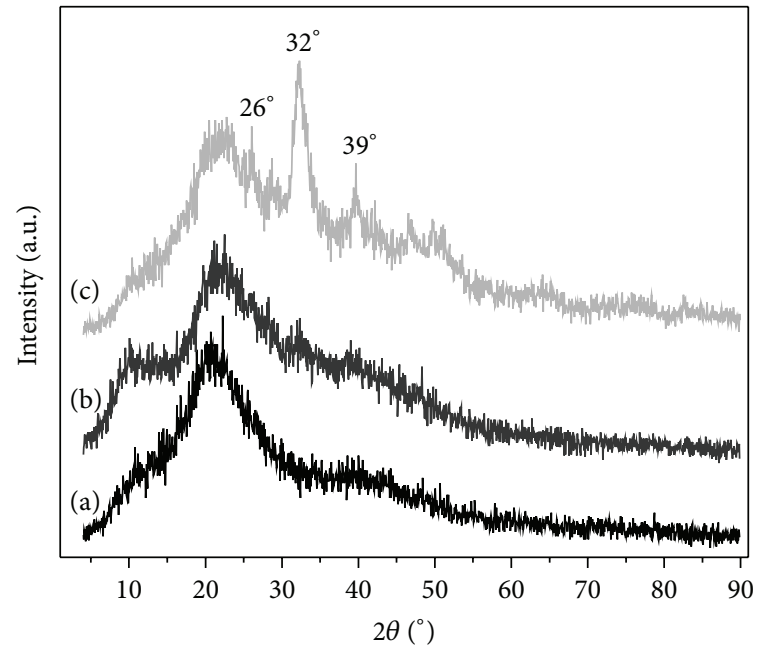

FIGURE 3: XRD film after seven days of immersion in SBF: (a) CS, (b) 10 , and (c) $20 \mathrm{wt} \%$ BG.

with $20 \mathrm{wt} \%$ of BG. The XRD patterns of the films containing 0 and $10 \mathrm{wt} \%$ glass exhibited broad peaks, indicating that the analyzed area has little or no crystallinity and therefore exhibits low bioactive property. Both the pure chitosan and the film with $10 \mathrm{wt} \%$ BG exhibited no diffraction peaks, indicating that these were amorphous materials. The film with $30 \mathrm{wt} \%$ BG was not examined by XRD because it was not possible to investigate its surface, due to the irregularities caused by it containing high concentration of BG.

3.3. In Vitro Cytotoxicity Assay. The mitochondrial activity of osteoblasts cultured with and without the presence of materials produced in this work was evaluated by the Resazurin test. This test is used to specifically assess mitochondrial 


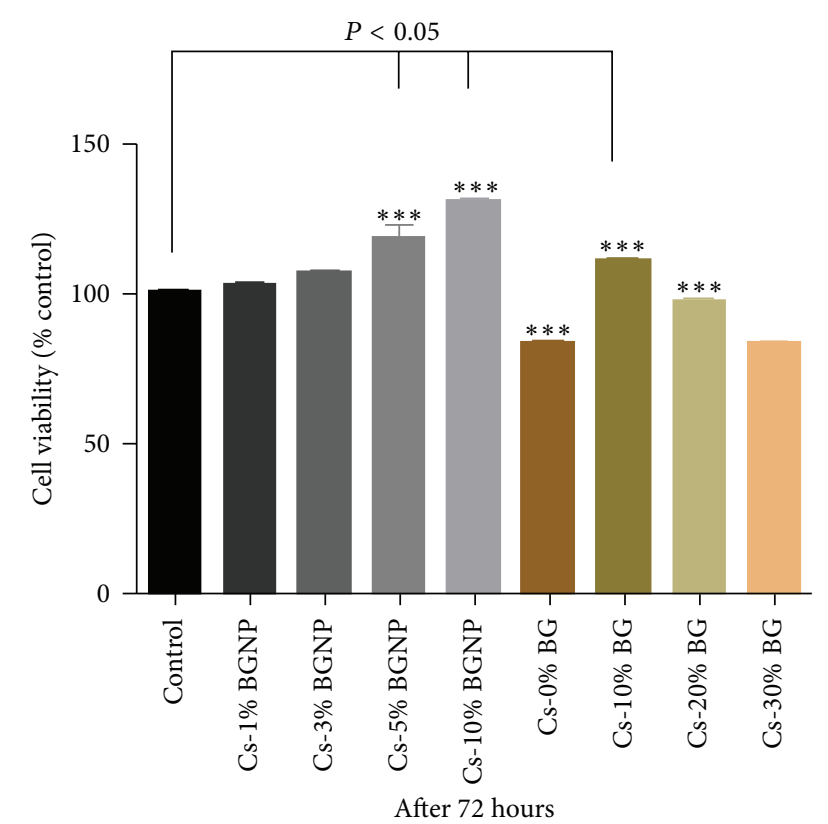

FIGURE 4: Cell viability of hybrid CS-BG and the CS-BGNP nanocomposites. ${ }^{*}$ Statistically significant difference $(P<0.05)$. Statistical analysis performed by ANOVA/Bonferroni/GraphPad Prism.

function and cell viability. Figure 4 illustrates the hybrid cell viability of hybrids (CS-BG) and the nanocomposites (CSBGNP). In the control group, the cells were seeded only by viable osteoblasts (no samples in the middle). In comparative groups, the cells were seeded on each film composition of the hybrid nanocomposites. Comparing the films analyzed with the control group after $72 \mathrm{~h}$, it can be concluded that as the content of the material BGNP increased, the cell viability also increased, and this difference was statistically significant $(P<0.05)$ for films with 5 and $10 \mathrm{wt} \%$ BGNP. The results indicated that cells plated on 5\% CS-BGNP exhibited an increase of $18 \pm 7.5 \%$ cell viability and the cells plated on CS-BGNP $10 \%$ exhibited an increase of $30 \pm 2 \%$ cell viability compared to the control group. The cells plated in $10 \%$ CS-BG exhibited a $10 \pm 1 \%$ increase in the cell viability. Studies in the literature identified that the higher cell viability compared to control when using bioactive glasses with $60 \%$ silica can be attributed to the ability of the ionic products from these materials to stimulate osteoblast proliferation [38]. Cells plated on CS 1\% BGNP and CS 3\% BGNP after $72 \mathrm{~h}$ exhibited a cell viability similar to that of the control group which was significantly higher compared to the viability of pure chitosan (CS 0\% BG). No significant differences in cell viability were found compared to the control group of cells plated on CS $20 \%$ BG. A decrease in cell viability was observed compared to the control group for cells plated on pure chitosan and $30 \mathrm{wt} \%$ CS-BG. The biological tests conducted with Resazurin in cells grown on the samples after $72 \mathrm{~h}$ indicated that samples containing nanoparticles of bioactive glass were more favorably increasing cell viability, but the results obtained by the hybrids CS-BG also induced
TABLE 2: Comparison of mean values of maximum stress and strain for the films CS-BGNP and CS-BG.

\begin{tabular}{lcc}
\hline $\begin{array}{l}\text { Sample } \\
(\text { wt } \%)\end{array}$ & $\begin{array}{c}\text { Maximum tensile } \\
\text { stress } \\
(\mathrm{MPa})\end{array}$ & $\begin{array}{c}\text { Maximum } \\
\text { deformation } \\
(\%)\end{array}$ \\
\hline CS & $42 \pm 5.5$ & $12 \pm 2.9$ \\
CS 1\% BGNP & $62 \pm 4.3$ & $14 \pm 2.2$ \\
CS 3\% BGNP & $73 \pm 5.2$ & $22 \pm 3.1$ \\
CS 5\% BGNP & $80 \pm 5.0$ & $21 \pm 3.1$ \\
CS 10\% BGNP & $68 \pm 4.6$ & $11 \pm 2.9$ \\
\hline CS 10\% BG & $53 \pm 7.0$ & $5 \pm 2.0$ \\
CS 20\% BG & $67 \pm 4.9$ & $4 \pm 0.9$ \\
CS 30\% BG & $\mathrm{X}$ & $\mathrm{X}$ \\
\hline
\end{tabular}

${ }^{*}$ Films for which tensile tests could not be performed.

a significant response from the cells because cell death was not markedly observed.

3.4. Tensile Testing. Figure 5(a) shows the stress-strain behavior relative to pure chitosan and films with 10 and $20 \mathrm{wt} \%$ of bioactive glass, each cross-linked with glutaraldehyde. In general, the behavior of the stress-strain curves is typical of a plastic material. It was observed that the films with bioactive glass decrease their percentage of elongation at break while they gradually increase its tensile strength. The bioactive glass behaves as typical reinforcing filler. The chitosan film exhibited a strength value of $42 \mathrm{MPa}$ and elongation at break of $11 \%$ (Table 2). The film with $10 \mathrm{wt} \%$ of bioactive glass increased its maximum strength to $53 \mathrm{MPa}$, while its elongation at break decreases to $5 \%$. The film containing $20 \%$ glass undergoes a large increase in the maximum tensile strength reaching values of $67 \mathrm{MPa}$, although its elongation at break decreases to $4 \%$. This behavior occurs due to interactions in the polymer network with the glass; the dispersion of the sol changes the chitosan matrix structure, leaving the hybrid with a less flexible structure, lessening its ductility compared to the films that did not undergo the addition of bioactive glass. Figure 5(b) illustrates the stress-strain curves for films of chitosan with 1, 3, 5, and 10\% BGNP, all of which are crosslinked with glutaraldehyde.

Tasselli et al. [23] investigated the mechanical properties of chitosan cross-linked with different glutaraldehyde content. For low contents of glutaraldehyde added an increase of the mechanical properties compared to pure chitosan was observed, unlike what was observed with higher contents added, for which the tensile strength decreased dramatically. Similar results were observed in this work. Although crosslinked chitosan produced in this work presented slightly smaller tensile strength than those found by the authors, the mechanical properties were significantly improved after the addition of BGNP.

The behavior in the tensile tests of nanocomposite films with BGNP is fairly similar to the behavior of the hybrid films with BG. The films exhibited a flexible behavior, and their stress-strain curves are typical of a plastic. The nanocomposite films were strongly influenced by the BGNP 


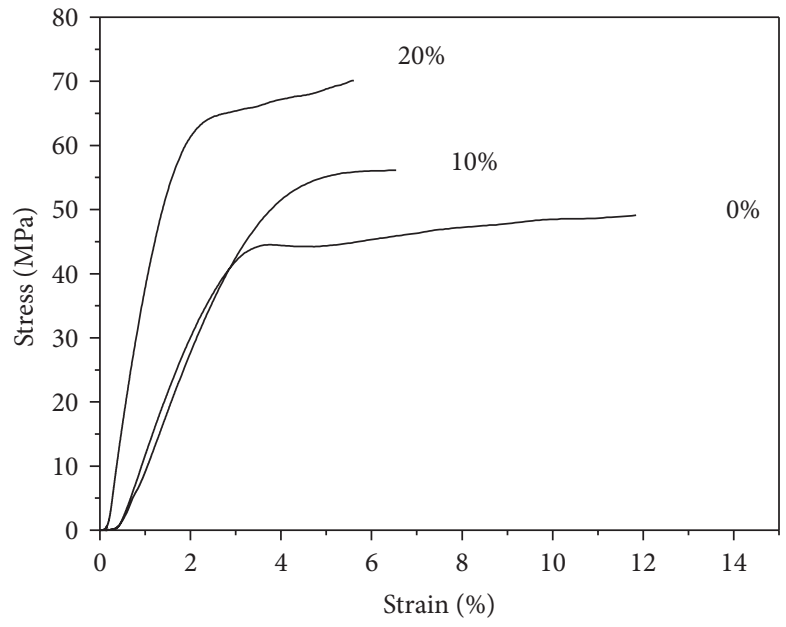

(a)

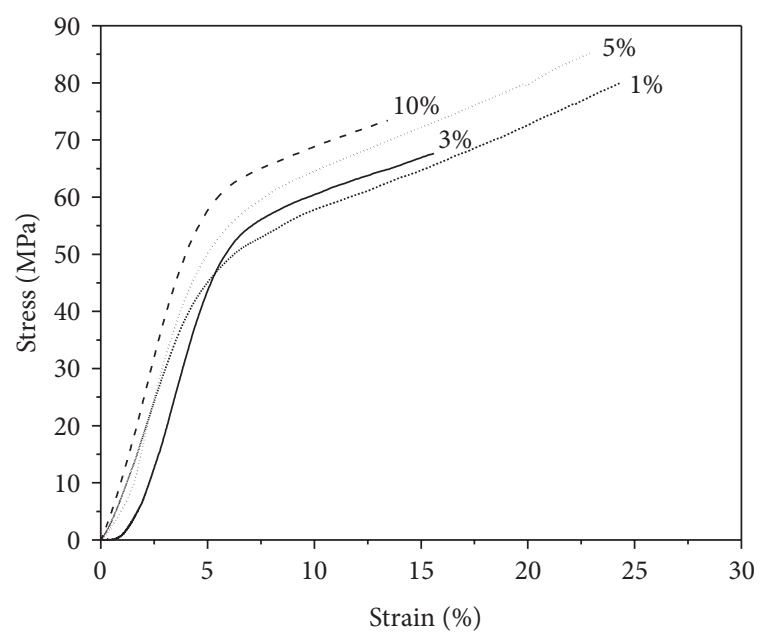

(b)

FIGURE 5: Stress-strain curves obtained from tensile testing of hybrid films with 0,10 , and $20 \mathrm{wt} \%$ in BG (a) and the nanocomposite films with $1,3,5$, and $10 \mathrm{wt} \%$ of BGNP (b).

content and exhibited high performance in comparison with the other hybrid films tested. Films with 3 and $5 \mathrm{wt} \%$ BGNP reached maximum strength values of $73 \mathrm{MPa}$ and $80 \mathrm{MPa}$, respectively. The elongation at break was also very significant, with percentages of $22 \%$ and $21 \%$ for films with $3 \mathrm{wt} \%$ and $5 \mathrm{wt} \%$ BGNP, respectively.

\section{Conclusions}

Hybrid composite films produced by homogeneous chitosan and bioactive glass have been successfully obtained using the two synthetic routes of sol-gel and coprecipitation, achieving adequate performance for the application as a guide to the cell growth of bone tissue. Both systems of CS-BG as CS-BGNP films exhibited high tensile strength and high bioactivity and cell viability. These results indicate that the use of bioactive glass successfully acted as an agent for loading and improved bioactivity, particularly in the form of nanoparticle dispersion (BGNP), whose results are the most promising.

\section{Conflict of Interests}

The authors declare that there is no conflict of interests regarding the publication of this paper.

\section{Acknowledgments}

The authors thank FAPEMIG, CAPES, and CNPq for the financial support of the work.

\section{References}

[1] S. I. Roohani-Esfahani, S. Nouri-Khorasani, Z. F. Lu, R. C. Appleyard, and H. Zreiqat, "Effects of bioactive glass nanoparticles on the mechanical and biological behavior of composite coated scaffolds," Acta Biomaterialia, vol. 7, no. 3, pp. 1307-1318, 2011.
[2] M. Peter, N. S. Binulal, S. Soumya et al., "Nanocomposite scaffolds of bioactive glass ceramic nanoparticles disseminated chitosan matrix for tissue engineering applications," Carbohydrate Polymers, vol. 79, no. 2, pp. 284-289, 2010.

[3] F. Al-Sagheer and S. Muslim, "Thermal and mechanical properties of chitosan $/ \mathrm{SiO}_{2}$ hybrid composites," Journal of Nanomaterials, vol. 2010, Article ID 490679, 7 pages, 2010.

[4] D. S. Couto, Z. Hong, and J. F. Mano, "Development of bioactive and biodegradable chitosan-based injectable systems containing bioactive glass nanoparticles," Acta Biomaterialia, vol. 5, no. 1, pp. 115-123, 2009.

[5] A. R. Boccaccini, M. Erol, W. J. Stark, D. Mohn, Z. Hong, and J. F. Mano, "Polymer/bioactive glass nanocomposites for biomedical applications: a review," Composites Science and Technology, vol. 70, no. 13, pp. 1764-1776, 2010.

[6] J. R. Jones, "New trends in bioactive scaffolds: the importance of nanostructure," Journal of the European Ceramic Society, vol. 29, no. 7, pp. 1275-1281, 2009.

[7] J. Mota, N. Yu, S. G. Caridade et al., "Chitosan/bioactive glass nanoparticle composite membranes for periodontal regeneration," Acta Biomaterialia, vol. 8, no. 11, pp. 4173-4180, 2012.

[8] K.-Y. Lee, M. Park, H.-M. Kim, Y.-J. Lim, H.-J. Chun, and S.-H. Moon, "Ceramic bioactivity: progresses, challenges and perspectives," Biomedical Materials, vol. 1, no. 2, pp. R31-R37, 2006.

[9] S. M. Carvalho, A. A. R. Oliveira, E. M. F. Lemos, and M. M. Pereira, "Bioactive glass nanoparticles for periodontal regeneration and applications in dentistry," in Nanobiomaterials in Clinical Dentistry, vol. 1, chapter 15, pp. 299-322, Elsevier, Waltham, Mass, USA, 2012.

[10] D. Lukito, J. M. Xue, and J. Wang, "In vitro bioactivity assessment of 70 (wt.) $\% \mathrm{SiO}_{2}-30$ (wt.) $\% \mathrm{CaO}$ bioactive glasses in simulated body fluid," Materials Letters, vol. 59, no. 26, pp. 32673271, 2005 .

[11] T. J. Webster, R. W. Siegel, and R. Bizios, "Osteoblast adhesion on nanophase ceramics," Biomaterials, vol. 20, no. 13, pp. 12211227, 1999.

[12] T. J. Webster, R. W. Siegel, and R. Bizios, "Nanoceramic surface roughness enhances osteoblast and osteoclast functions for 
improved orthopaedic/dental implant efficacy," Scripta Materialia, vol. 44, no. 8-9, pp. 1639-1642, 2001.

[13] M. N. V. R. Kumar, R. A. A. Muzzarelli, C. Muzzarelli, H. Sashiwa, and A. J. Domb, "Chitosan chemistry and pharmaceutical perspectives," Chemical Reviews, vol. 104, no. 12, pp. 60176084, 2004.

[14] M. M. Pereira, J. R. Jones, and L. L. Hench, "Bioactive glass and hybrid scaffolds prepared by sol-gel method for bone tissue engineering," Advances in Applied Ceramics, vol. 104, no. 1, pp. 35-42, 2005.

[15] E.-J. Lee, D.-S. Shin, H.-E. Kim, H.-W. Kim, Y.-H. Koh, and J.-H. Jang, "Membrane of hybrid chitosan-silica xerogel for guided bone regeneration," Biomaterials, vol. 30, no. 5, pp. 743-750, 2009.

[16] L. Dupoirieux, D. Pourquier, M. C. Picot, and M. Neves, "Comparative study of three different membranes for guided bone regeneration of rat cranial defects," International Journal of Oral and Maxillofacial Surgery, vol. 30, no. 1, pp. 58-62, 2001.

[17] N. M. Alves and J. F. Mano, "Chitosan derivatives obtained by chemical modifications for biomedical and environmental applications," International Journal of Biological Macromolecules, vol. 43, no. 5, pp. 401-414, 2008.

[18] C. Chatelet, O. Damour, and A. Domard, "Influence of the degree of acetylation on some biological properties of chitosan films," Biomaterials, vol. 22, no. 3, pp. 261-268, 2001.

[19] M. Peter, P. T. Sudheesh Kumar, N. S. Binulal, S. V. Nair, H. Tamura, and R. Jayakumar, "Development of novel $\alpha$ chitin/nanobioactive glass ceramic composite scaffolds for tissue engineering applications," Carbohydrate Polymers, vol. 78, no. 4, pp. 926-931, 2009.

[20] A. Lahiji, A. Sohrabi, D. S. Hungerford, and C. G. Frondoza, "Chitosan supports the expression of extracellular matrix proteins in human osteoblasts and chondrocytes," Journal of Biomedical Materials Research Part A, vol. 51, pp. 586-595, 2000.

[21] Y. Zhang and M. Zhang, "Synthesis and characterization of macroporous chitosan/calcium phosphate composite scaffolds for tissue engineering," Journal of Biomedical Materials Research Part A, vol. 55, pp. 304-312, 2001.

[22] L. Kong, Y. Gao, G. Lu, Y. Gong, N. Zhao, and X. Zhang, "A study on the bioactivity of chitosan/nano-hydroxyapatite composite scaffolds for bone tissue engineering," European Polymer Journal, vol. 42, no. 12, pp. 3171-3179, 2006.

[23] F. Tasselli, A. Mirmohseni, M. S. Seyed Dorraji, and A. Figoli, "Mechanical, swelling and adsorptive properties of dry-wet spun chitosan hollow fibers crosslinked with glutaraldehyde," Reactive and Functional Polymers, vol. 73, no. 1, pp. 218-223, 2013.

[24] A. A. R. de Oliveira, V. S. Gomide, M. de Fátima Leite, H. S. Mansur, and M. de Magalhäes Pereira, "Effect of polyvinyl alcohol content and after synthesis neutralization on structure, mechanical properties and cytotoxicity of sol-gel derived hybrid foams," Materials Research, vol. 12, no. 2, pp. 239-244, 2009.

[25] M. Rolón, C. Vega, J. A. Escario, and A. Gómez-Barrio, “Development of resazurin microtiter assay for drug sensibility testing of Trypanosoma cruzi epimastigotes," Parasitology Research, vol. 99, no. 2, pp. 103-107, 2006.

[26] D. Liu, "A rapid biochemical test for measuring chemical toxicity," Bulletin of Environmental Contamination and Toxicology, vol. 26, no. 2, pp. 145-149, 1981.

[27] R. K. Pettit, C. A. Weber, M. J. Kean et al., "Microplate alamar blue assay for Staphylococcus epidermidis biofilm susceptibility testing," Antimicrobial Agents and Chemotherapy, vol. 49, no. 7, pp. 2612-2617, 2005.

[28] J. O'Brien, O. Wilson, T. Orton, and F. Pognan, "Investigation of the Alamar blue (resazurin) fluorescent dye for the assessment of mammalian cell cytotoxicity," European Journal of Biochemistry, vol. 267, no. 17, pp. 5421-5426, 2000.

[29] International Organization for Standardization, "Implants for surgery-in vitro evaluation for apatite-forming ability of implant materials," ISO 23317, 2007.

[30] ASTM D882-12, Standard Test Method for Tensile Properties of Thin Plastic Sheeting, American Society for testing and Materials International, West Conshohocken, Pa, USA.

[31] C. E. Bayliss and W. M. Waites, "The combined effect of hydrogen peroxide and ultraviolet irradiation on bacterial spores," Journal of Applied Bacteriology, vol. 47, no. 2, pp. 263269, 1979.

[32] C. J. Stannard, J. S. Abbiss, and J. M. Wood, "Combined treatment with hydrogen peroxide and ultra-violet irradiation to reduce microbial contamination levels in pre-formed food packaging cartons," Journal of Food Protection, vol. 46, no. 12, pp. 1060-1064, 1983.

[33] W. M. Waites, S. E. Harding, D. R. Fowler, S. H. Jones, D. Shaw, and M. Martin, "The destruction of spores of Bacillus subtilis by the combined effects of hydrogen peroxide and ultraviolet light," Letters in Applied Microbiology, vol. 7, no. 5, pp. 139-140, 1988.

[34] O. Peitl, E. Dutra Zanotto, and L. L. Hench, "Highly bioactive $\mathrm{P}_{2} \mathrm{O}_{5}-\mathrm{Na}_{2} \mathrm{O}-\mathrm{CaO}-\mathrm{SiO}_{2}$ glass-ceramics," Journal of NonCrystalline Solids, vol. 292, no. 1-3, pp. 115-126, 2001.

[35] P. Sepulveda, J. R. Jones, and L. L. Hench, "In vitro dissolution of melt-derived $45 \mathrm{~S} 5$ and sol-gel derived $58 \mathrm{~S}$ bioactive glasses," Journal of Biomedical Materials Research, vol. 61, no. 2, pp. 301311, 2002.

[36] R. Jayakumar, D. Menon, K. Manzoor, S. V. Nair, and H. Tamura, "Biomedical applications of chitin and chitosan based nanomaterials-a short review," Carbohydrate Polymers, vol. 82, no. 2, pp. 227-232, 2010.

[37] X. Cai, H. Tong, X. Shen, W. Chen, J. Yan, and J. Hu, "Preparation and characterization of homogeneous chitosan-polylactic acid/hydroxyapatite nanocomposite for bone tissue engineering and evaluation of its mechanical properties," Acta Biomaterialia, vol. 5, no. 7, pp. 2693-2703, 2009.

[38] P. Valerio, M. H. R. Guimaráes, M. M. Pereira, M. F. Leite, and A. M. Goes, "Primary osteoblast cell response to sol-gel derived bioactive glass foams," Journal of Materials Science: Materials in Medicine, vol. 16, no. 9, pp. 851-856, 2005. 

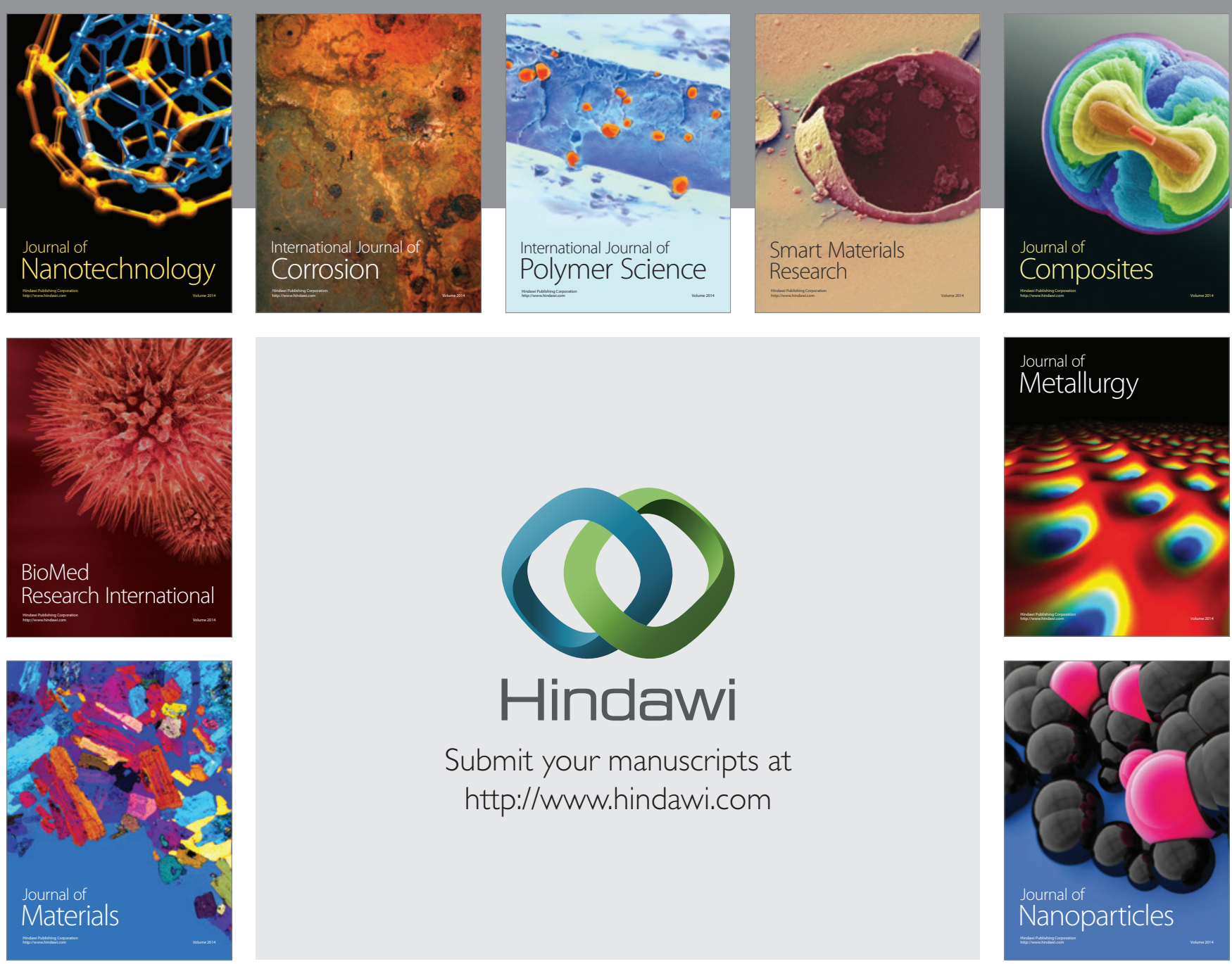

Submit your manuscripts at http://www.hindawi.com
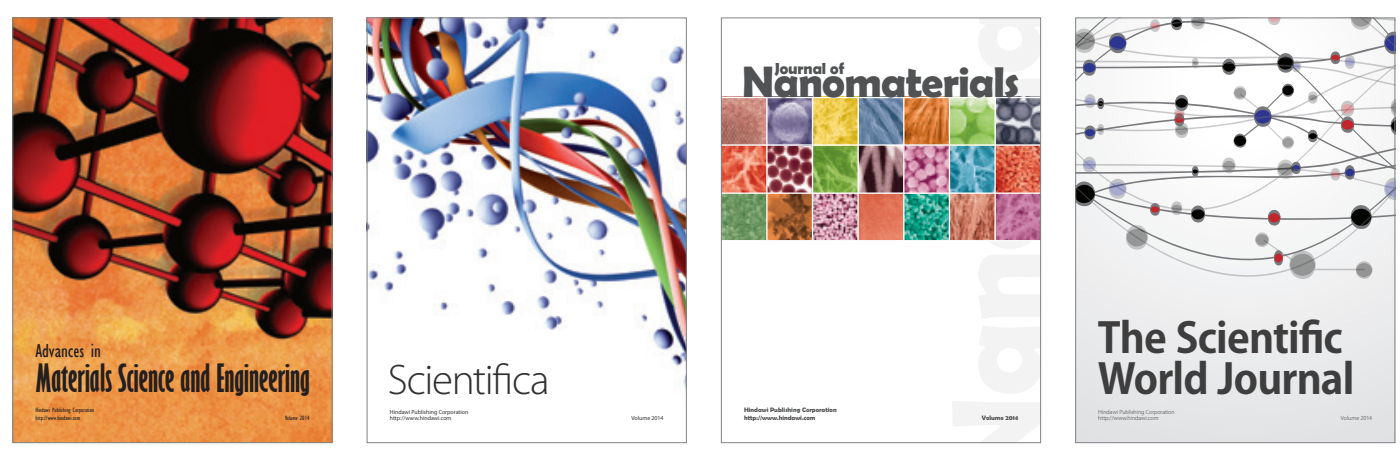

\section{The Scientific World Journal}
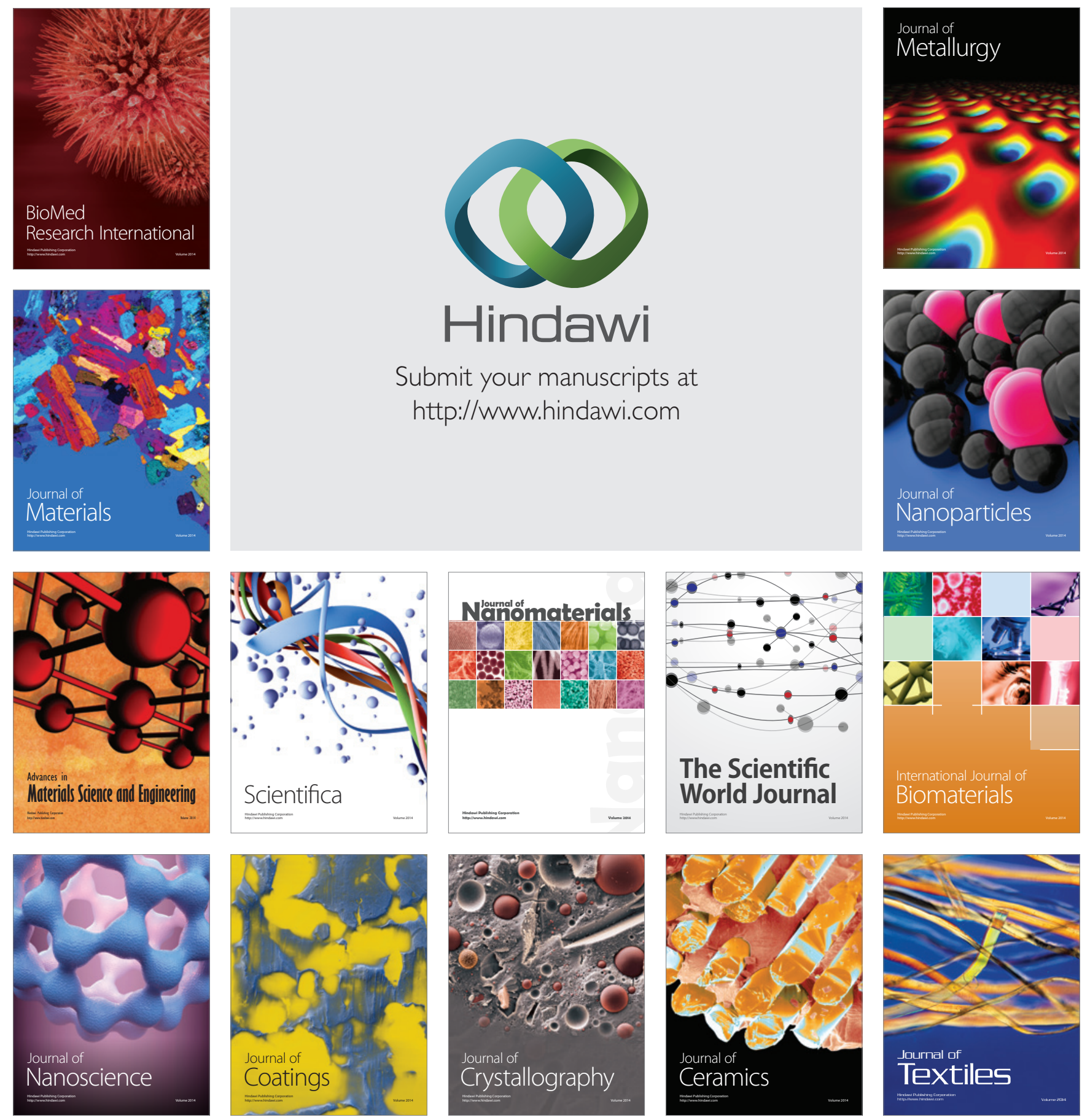